\title{
Barriers to research activities as perceived by medical university students: A cross-sectional study
}

\author{
Sakineh Dadipoor, Ali Ramezankhani ${ }^{1}$, Teamur Aghamolaei, Ali Safari-Moradabadi²
}

Department of Public Health, School of Public Health, Hormozgan University of Medical Sciences, Bandar Abbas, ${ }^{1}$ Department of Public Health, School of Public Health and Safety, Shahid Beheshti University of Medical Sciences, Tehran, ${ }^{2}$ Student Research Committee, School of Public Health and Safety, Shahid Beheshti University of Medical Sciences, Tehran, Iran

\begin{tabular}{|c|}
\hline Access this article online \\
\hline Website: www.avicennajmed.com \\
\hline DOI: 10.4103/ajm.AJM_121_18 \\
\hline Quick Response Code: \\
\hline
\end{tabular}

\begin{abstract}
Context: The importance of research is revealed by the fact that the top seven science producing countries in the world are the same seven countries worldwide in terms of the research facilities. Aim: To explore the barriers to research activities among the students of the Hormozgan Medical University. Settings and Design: A total of 400 students affiliated with the Hormozgan University of Medical Sciences participated in this cross-sectional study. Methods: The sampling method was proportional stratified, and the data collection instrument was a tripartite questionnaire that comprised demographic information, personal barriers, and organizational barriers. Statistical analysis: The data were statistically analyzed by the Statistical Package for the Social Sciences (SPSS) software (V.16.0, SPSS Inc., Chicago, IL, USA) using descriptive statistics as well as the independent sample $t$-test, one-way analysis of variance, and Pearson's correlation coefficient. The level of significance was set at $P<0.05$. Results: The most prevalent personal barriers were inadequate knowledge of research methodology $(2.91 \pm 1.24)$ and inadequate skill in research conduction $(2.89 \pm 1.36)$. In the realm of organizational barriers, limited access to information sources was the most prevalent barrier $(2.75 \pm 2.27)$. The results showed that researcher students encounter more of the organizational barriers $(56.13 \pm 13.90)$, whereas non-researcher students faced more of the personal barriers (53.80 \pm 10.95$)$. Conclusion: Establishing access to high-speed Internet system, raising students' awareness of research methodology through workshops, encouraging and motivating students for research work, and using online sources can help in removing the barriers to research activities.
\end{abstract}

Key words: Barriers, Hormozgan, research, students, university

\section{INTRODUCTION}

Scientific research is a systematic study aiming to solve a problem and is the main stimulus in a society to guarantee its development and is considered a key growth indicator. ${ }^{[1]}$ The importance of research is revealed by the fact that the top seven science producing countries in the world are the same seven countries worldwide in terms of the research facilities, and underdeveloped or underdeveloped countries differ from these developed countries in research opportunities and facilities. The difference between the developed and developing countries lies in the research facilities, conditions, and domains. ${ }^{[2]}$ In fact, developing countries do not use

Address for correspondence: Mr. Ali Safari-Moradabadi, Student Research Committee, School of Public Health and Safety, Shahid Beheshti University of Medical Sciences, Tehran, Iran. E-mail: alisafari_31@yahoo.com research instruments to recognize and solve problems and that is why they are incapable of meeting their needs scientifically. Therefore, developing countries are mainly consumers of the scientific findings of the developed countries, mostly published in the academic journals of the same countries. ${ }^{[3]}$

Nowadays, countries are classified according to their ability to generate and apply the knowledge. Knowledge production and scientific development are known as the all-out power

This is an open access journal, and articles are distributed under the terms of the Creative Commons Attribution-NonCommercial-ShareAlike 4.0 License, which allows others to remix, tweak, and build upon the work non-commercially, as long as appropriate credit is given and the new creations are licensed under the identical terms.

For reprints contact: reprints@medknow.com

Cite this article as: Dadipoor S, Ramezankhani A, Aghamolaei T, Safari-Moradabadi A. Barriers to research activities as perceived by medical university students: A cross-sectional study. Avicenna J Med 2019;9:8-14. 
of the countries. ${ }^{[4]}$ The universities and higher educational centers of the Iranian health ministry and medical education have three tasks including production of knowledge, transfer of knowledge, and providing specialized services to the society. Optimal performance in any of the aforementioned tasks requires scientific research. ${ }^{[5]}$

As universities are the main scientific core of the societies, it is the duty of the universities to perform a great portion of the research works. ${ }^{[6]}$ This duty in the universities is handled by the students and faculty members. However, unfortunately, research findings have shown that the time spent by most of the faculty members in the universities is on education. That is why, the majority of faculty members at universities in developing countries spend little time for research. ${ }^{[2]}$

According to a document entitled "Being a faculty member in the 20th century," each faculty member is active more than he/she is capable of (i.e., $40 \mathrm{~h}$ a week). In an informal survey, the working hours of the faculty members were reported to be as high as $60 \mathrm{~h}$ per week. ${ }^{[7]}$ However, according to an investigation by Unnikrishnan et al. ${ }^{[8]}$ the faculty members spend only $1-5 \mathrm{~h}$ per week on research works with students because of the intensive work schedules, teaching, and clinical practices.

University students play a key role in the development of a country as future researchers. ${ }^{[9]}$ However, it is impossible to use the creative talents of students in knowledge production and national development without familiarizing them with research activities. ${ }^{[10]} \mathrm{A}$ body of research shows that the research activities of university students can lead to the development of critical thinking, enrichment of group works, promotion of research evaluation capabilities, and gaining the experience and skills needed in different healthrelated domains. ${ }^{[11-13]}$ Some studies in Iran and worldwide have investigated the barriers to research activities in the university context. ${ }^{[8,14,15]}$

Student research in universities is of great importance, and university authorities should be made aware of the research barriers of students. Moreover, 70\% of medical students are not willing to carry out research because of the existing barriers and challenges including the lack of access to information sources, lack of expertise in English, administrative restrictive regulations, insufficient research budgets, and inability to write formal research proposals. ${ }^{[14,16,17]}$ Therefore, it is essential to investigate the barriers to research activities of university students. The majority of researches in Iran have explored the research barriers of faculty members, and less attention has been paid to the research barriers of university students. ${ }^{[5,18,19]}$ Therefore, this study aimed to explore the barriers to research activities as perceived by the students of the Bandar Abbas University.

\section{SUBJECTS AND METHODS}

\section{Research design}

In this cross-sectional study, the research population consisted of medical students affiliated with Bandar Abbas University in 2016. The sample size was estimated based on similar studies and using a formula, whereas the maximum $P$ level was set at $0.5,{ }^{[20]}$ the confidence level was set at $95 \%$, and the estimated error was $5 \%$. The final sample size was decided to be 400 . The participant students were divided in two groups of researcher and non-researcher students. The former was defined as a student with an experience of research activity such as involvement in research projects, paper presentation in national and international conferences, and paper publication in Persian or English journals. The latter was defined as a student who had none of the aforementioned features. The sample subjects were selected through proportional stratified random sampling. In this regard, each faculty was taken as a stratum. Later, the required subjects were selected from each stratum, proportional to the size of each stratum, using a simple randomized method. Therefore, a total of 400 research subjects were selected, which consisted of 92 health faculties, 61 nursing faculties, 100 paramedical, 90 medical, and 57 dental students.

\section{Instrument}

The data collection instrument was a tripartite questionnaire. Initial part comprised demographic information, second part was related to personal barriers that comprised 10 items, and the final section concerned with organizational barriers and included 21 items. The second and third sections of the questionnaire was scored using a Likert scale extending from "totally agree" (scored 5) to "totally disagree" (scored 1). Moreover, an overall score was calculated for each item. A higher score would imply more agreement with the existence of barriers to research works. The mean score of each domain (personal or organizational) was estimated of 100 . The target questionnaire was developed based on the review of the related literature and scientific sources. Both quantitative and qualitative procedures were followed to establish the face validity of the questionnaire. For the qualitative face validation, 20 university students were interviewed face to face. The difficulty level (difficulty of comprehending the statements), relevance (relevance of the statements to the dimensions of the questionnaire), and ambiguity (probability of misunderstandings or failure to 
understand the meanings of statements) of the items were investigated. Once the corrections were made, the next step was to reduce the statements, discard redundancies, and set the significance of each statement through the quantitative method of estimating the impact of items. In this method, each item of the questionnaire was rated on a five-level Likert scale: totally significant, 5 ; to some extent significant, 4 ; moderately significant, 3 ; a little significant, 2 ; and totally not significant, 1 .

\section{Validity and reliability}

For content validation, the questionnaire was available to five faculty members to check the simplicity, relevance, and clarity of each statement. To establish the reliability, the testretest method was used. With this aim, the questionnaire was provided to a group of 30 subjects twice with an interval of 10 days, and the resulted data were checked for correlation.

\section{Ethical considerations}

All the students participated in the study voluntarily. They signed an informed consent form before participation, and the confidentiality of data was guaranteed. In addition, the research was approved by the ethical committee of the Hormozgan University of Medical Sciences.

\section{Data analysis}

The collected data were analyzed by the Statistical Package for the Social Sciences (SPSS) software (V. 16.0, SPSS Inc., Chicago, IL, USA), through descriptive statistics such as mean, standard deviation, frequency, and percentage. Inferential statistics were also used, including the independent samples $t$-test, one-way analysis of variance, and Pearson's correlation coefficient. The significance level was set at $P<0.05$.

\section{RESULTS}

The age range of the subjects was 17-35 years and the mean age was $21.61 \pm 2.61$ years. Approximately $55.9 \%(n=227)$ of the subjects were females, $21.4 \%(n=87)$ had an experience in research activities, and $24.1 \%(n=98)$ had attended academic workshops.

In this research, the main personal barrier to research activities was found to be inadequate skill and knowledge of research methodology. On the other hand, family responsibility was reported to be the least important barrier to research [Figure 1].

In the realm of organizational barriers, limited access to information sources and limited facilities and equipment were the major barriers, whereas clinical services to research activities provided to patients were the minor barriers to research [Figure 2].

According to the present findings, no statistically significant correlation was observed between personal barriers to research and age $(P=0.975)$. Similarly, no statistically significant correlation was found between organizational barriers and age $(P=0.809)$.

The results revealed that researcher students faced organizational barriers more $(56.13 \pm 13.90)$, whereas non-researcher students faced personal barriers more $(53.8 \pm 10.95)$. On the whole, organizational barriers were more prevalent than personal barriers [Figure 3, Table 1].

\section{DISCUSSION}

This study revealed that the most prevalent barriers to research activities among researchers and non-researcher students were organizational and personal barriers, respectively. These findings are consistent with Anbari and Jadidi, ${ }^{[10]}$ Siemens et al. ${ }^{[21]}$ and Amin et al. ${ }^{[22]}$ Naturally, researcher students are involved more than non-researcher students in the bureaucracy of approving research proposals, which is perceived as an organizational barrier. Among the existing organizational barriers, the limited access to information sources, lack of facilities and equipment, timeconsuming bureaucracy, inadequate income of research activities, and demotivating authorities and professors are the most frequently reported research barriers.

According to the present findings, the most important organization barrier was limited access to information sources. This finding is in line with Farzaneh et al. ${ }^{[14]}$ and Ibrahim Abushouk et al. ${ }^{[23]}$ Amin et al. ${ }^{[22]}$ Siemens et al., ${ }^{[21]}$ Majumder, ${ }^{[24]}$ Sumathipala et al. ${ }^{[25]}$ and Bagheri Majd et al. ${ }^{[26]}$ reported failure in increasing the knowledge as the main disaster in research institutes. It seems that the high publication cost of some specialized journals, lack of training and good mentorship, and research budget shortage are some of the underlying reasons for the current findings. ${ }^{[17,23,27]}$

The second most prevalent organizational barrier was limited facilities and equipment. An investigation of the countries, which developed significantly in the recent years, showed their appropriate investment (financial, human force, etc.) in the realm of research. ${ }^{[28]}$ In their investigation of the main challenges to research, Shekari and Zavari ${ }^{[29]}$ realized that the competition in the developing countries has made the private sector to play a key role in providing funds for research works. But it is not the case in Iran 


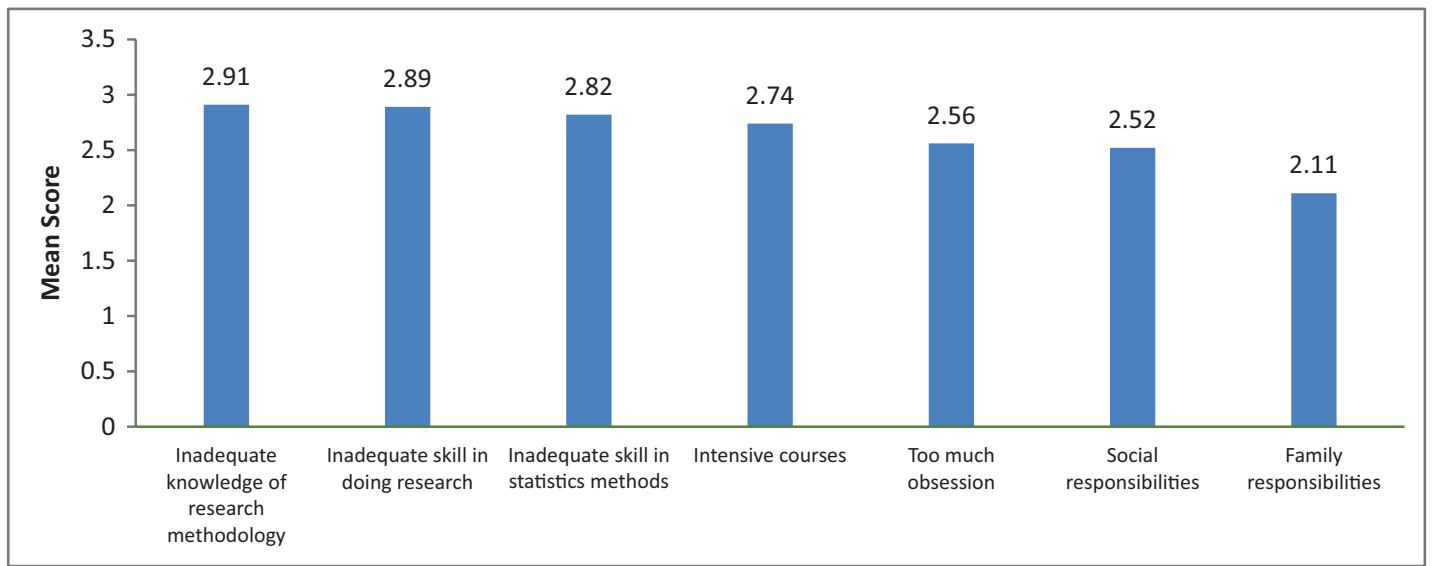

Figure 1: Mean score of personal barriers to research activities

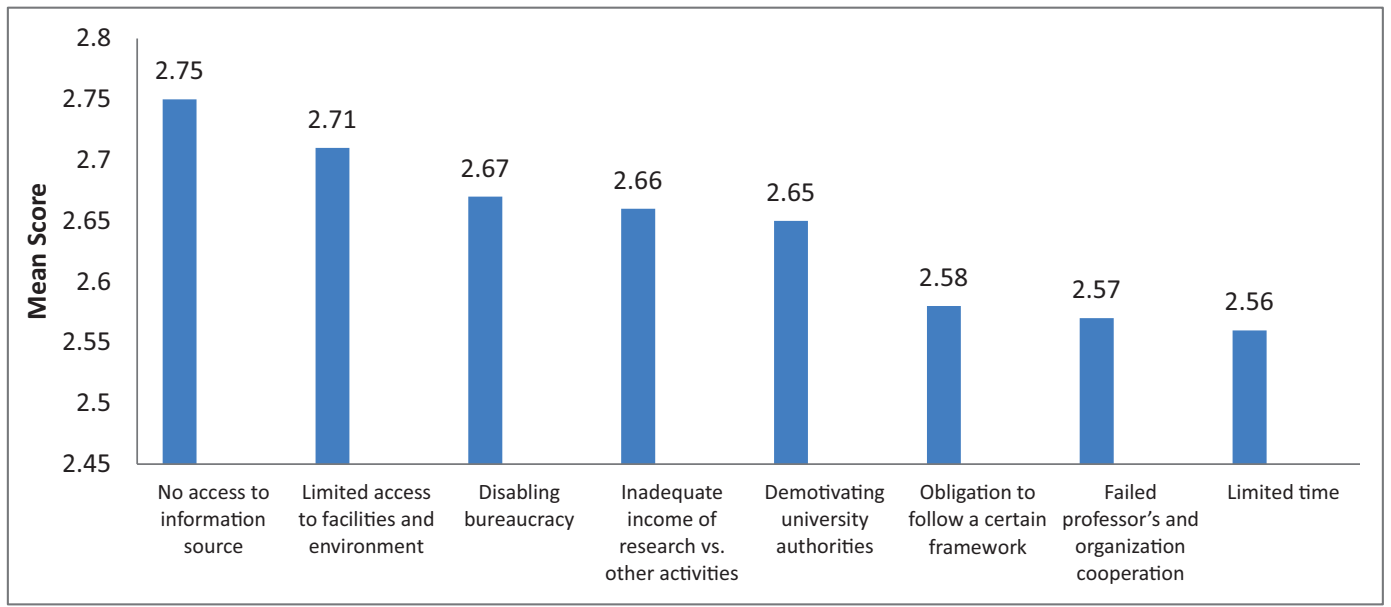

Figure 2: Mean score of organizational barriers to research activities

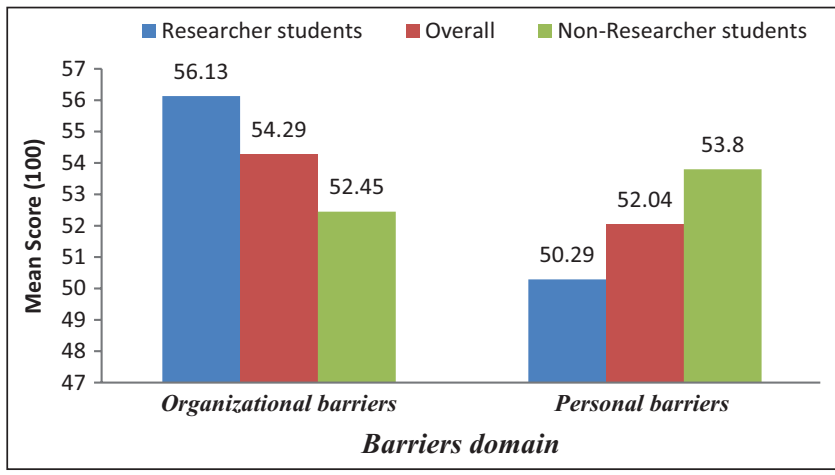

Figure 3: Researcher and non-researcher students' mean scores of barriers to research activities

and many other developing countries. ${ }^{[29]}$ Hegde et al. ${ }^{[27]}$ reported that the most important barrier to conducting research was the lack of funding from the institutions. In another study by Unnikrishnan et al. ${ }^{[8]}$ one barrier to conducting research and supporting students, as perceived by the faculty members, was limited sources and facilities and limited access. In another research by Bocar, ${ }^{[30]}$ the majority of students mentioned financial problems as a barrier to research.
In the research by Ghaffarzadeh et al., ${ }^{[31]}$ more than half of the subjects believed that the existing facilities and equipment as well as the financial sources at university are inadequate for research activities. The findings by Safari et al. ${ }^{[32]}$ revealed that educational and research-based facilities, access to high-speed Internet and various databases, well-equipped labs and advanced lab devices, and financial support for students' research by the university research centers all can enhance student participation in research activities. Many other studies also reported similar findings. ${ }^{[33-36]}$ Thus, it can be concluded that more the national research budget, more the student participation in the research works. With this respect, the authorities are suggested to pay special attention to research budgets, especially of students' research.

Long and time-consuming process of approving research proposals and demotivation of students by faculty members and other authorities were among the other barriers mentioned by students. In the study performed in 2017, Alsied and Ibrahim ${ }^{[37]}$ referred to the low motivation of students to conduct any research. Similarly, in an investigation in 2014 conducted in Indian University, a 


\begin{tabular}{|c|c|c|c|}
\hline \multicolumn{4}{|c|}{$\begin{array}{l}\text { Table I: Comparison of the mean score of barriers to } \\
\text { research activities in researcher and non-researcher } \\
\text { students }\end{array}$} \\
\hline $\begin{array}{l}\text { Barriers to research } \\
\text { activities }\end{array}$ & $\begin{array}{l}\text { Researcher } \\
\text { students }\end{array}$ & $\begin{array}{c}\text { Non-researcher } \\
\text { students' }\end{array}$ & $P$ value \\
\hline Organizational barriers & $56.13 \pm 13.90$ & & \\
\hline Personal barriers & $50.29 \pm 13.90$ & $53.80 \pm 10.95$ & 0.021 \\
\hline
\end{tabular}

major barrier to research by the students of higher education was reported to be the demotivation issue. Moreover, the same research found motivating and encouraging actions as essential to improve the current state of research for students and faculty members. They also suggested student participation in research methodology workshops. ${ }^{[8]}$ In an investigation in 2010, which aimed to investigate research barriers in three Canadian universities, the lack of proper encouragement or support to engage in research activities was found to be a significant barrier. ${ }^{[21]}$

The supervisors can play a key role in motivating students to conduct academic research by emphasizing on the benefits of research for their future life and occupation. Moreover, the investment on and establishment of active student research committees, giving certain permissions to these committees, and employing active students as the workforce in these committees, and paying them can be regarded as effective motivators. In his study, Azizi ${ }^{[38]}$ concluded that the consideration of intrinsic factors (motivation), facilitating the growth of talents and their creativity, attention to financial factors, and use of information systems are the keys to research. Considering the proposal approval procedures, research findings have shown that approximately $85 \%$ of those sending their proposals to university research centers perceived this procedure to be unnecessarily long and timeconsuming. Thus, it is essential to revise the structures and procedures of universities and their research centers. Moreover, the experiences of the research center managers can be used for the improvement of the bureaucratic procedures in the approval of research proposals. ${ }^{[39]}$ Therefore, removing official barriers, developing the notification systems, and employing qualified and experienced individuals to evaluate research proposals can be considered for shortening the approval procedure of long research proposals.

The present findings showed that inadequate skill and knowledge of research methodology are the main personal barriers to student participation in research. In the study by Ibrahim Abushouk et al., ${ }^{[23]}$ the inadequate understanding of the concepts of research, especially the statistical concepts and lack of skill in scientific writing were the barriers to research. In a research by Siemens et al., ${ }^{[21]}$ inadequate knowledge and training in research were the barriers to research in students. In a study by Bocar, ${ }^{[30]}$ the lack of skill in analyzing and interpreting the results was one of the obstacles to research in the majority of students.

In their research, Ashrafi-Rizi et al. ${ }^{[35]}$ mentioned students' inadequate skill and knowledge of research methodology among the main personal barriers to research. This finding was consistent with the body of other research findings. ${ }^{[15,21,33,40,41]}$ However, it was different from the findings of Abedini et al., ${ }^{[42]}$ concerning the research skills in their target population. It seems that the difference lies in the fact that in the research by Abedini et al. ${ }^{[42]}$ the target population was faculty members, whereas in this research, it was students. Inclusion of the research methodology courses at different university levels as well as holding regular practical workshops can increase the knowledge of students in research methodology. Joibari and Sanagoo ${ }^{[43]}$ have mentioned research methodology in the students' curriculum as a top priority.

According to the present findings, university students rated high workload and intensive courses among the key barriers to research. This finding is consistent with that of the studies by Anbari and Jadidi, ${ }^{[10]}$ Ashtyani and Shamsi, ${ }^{[16]}$ Poornaseri et al., ${ }^{[44]}$ Kharraz et al., ${ }^{[17]}$ Russell et al., ${ }^{[45]}$ and Oliveira et al. ${ }^{[46]}$ Naturally, high workload of medical students in clinics during education and their intensive courses set limits on their research activities even when there are enough research facilities. The study by Edwards ${ }^{[4]}$ also showed that intensive courses are among the main barriers to research activities. To remove this research barrier, Houlden et al. ${ }^{[48]}$ recommended the introduction of summer research courses in the students' curriculum. A successful example in this regard is the experience of the undergraduate research committee in Saudi Arabia in giving national and international research opportunities to the undergraduate students during the summer of 2010-2013 with substantial qualitative (learning) and quantitative (publication) outcomes. ${ }^{[49]}$

\section{LIMITATION}

One limitation of this research is that the questionnaire used was developed by the present researchers based on the related body of literature. Its validity was tested based on the comments made by experts and faculty members, and its reliability was estimated through Cronbach's alpha. Further research is suggested to validate the questionnaire through psychometrics, especially factor analysis. Another limitation was that the questionnaire was self-rating in type and might suffer from insufficient accuracy. This research was conducted on the students of the Hormozgan University of Medical Sciences. Thus, the results can be generalized to 
other contexts and universities with caution because of the existing differences. Another limitation of this study was the lack of students' cooperation in filling the questionnaires. Furthermore, the questions of the questionnaire were of the closed type, which limits it for revealing more research barriers.

\section{CONCLUSION}

According to the present findings, inadequate skill and knowledge in research methodologies, limited access to information sources, and limited facilities are the main barriers to research in university students. Holding theoretical and practical research methodology courses, forming a responsive and helpful research team assistant to support students and providing them with the required facilities/equipment, and giving more financial support for the students research activities can help to remove the existing barriers to research.

\section{Acknowledgments}

This research was part of a project coded as 1396/37331 approved by the Student Research Committee of the Shahid Beheshti University of Medical Sciences in Tehran, Iran. We are grateful to the Student Research Committee and the Research and Technology Chancellor in the target university for their financial support.

\section{Financial support and sponsorship}

This study was funded by the Deputy of Research and Technology of the Shahid Beheshti University of Medical Sciences.

\section{Conflicts of interest}

There are no conflicts of interest.

\section{REFERENCES}

1. Batooli Z, Nazari M. The features of social research network for facilitating research activities from medical sciences researchers' perspective. J Payavard Salamat 2014;8:316-31.

2. Sotodeh Asl N, Ghorbani R, Rashidy-Pour A. Viewpoints of faculty members of Semnan University of Medical Sciences about research barriers. Koomesh 2014;16:1-7.

3. Canagarajah AS. "Nondiscursive" requirements in academic publishing, material resources of periphery scholars, and the politics of knowledge production. Written Commun 1996;13:435-72.

4. Sereshti M, Kazemiyan A, Edris F. Barriers of research form perspective of professors and Shahrekord Medical university staff. Res Strategy Magazine 2010;3:51-7.

5. Alamdari A, Afshoon E. Obstacles to conducting research activities from the viewpoint of faculty members in Yasuj. Armaghan Danesh Magazine 2010;8:27-34.

6. Rezaeian M, Zare-Bidaki M, Bakhtar M, Hadimoghadam M. A survey of research self-efficacy in internship medical students of Rafsanjan
University of Medical Sciences in 2013. J Rafsanjan Uni Med Sci 2015;14:111-24.

7. Pollack M. Being a faculty member in the 21 st century. 2014. Available at: https://www.provost.umich.edu/reports/Being\%20A\%20Faculty\%20 Member\%2021\%20Century\%20Report.pdf

8. Unnikrishnan B, Kanchan T, Holla R, Kumar N, Rekha T, Mithra P, et al. Medical students' research—facilitators and barriers. J Clin Diagn Res 2014;8:XC01-4.

9. Cohen MD, Jennings SG. Agreement and reproducibility of subjective methods of measuring faculty time distribution. Acad Radiol 2002;9:1201-8.

10. Anbari Z, Jadidi RA. Comparing of barriers to research activities among students of Arak University of Medical Sciences, and appropriate strategies for student research management. Iran J Med Edu 2013;13:435-48. [Persian].

11. Frishman WH. Student research projects and theses: Should they be a requirement for medical school graduation? Heart Dis 2001;3:140-4.

12. Burazeri G, Civljak M, Ilakovac V, Janković S, Majica-Kovačević T, Nedera $\mathrm{O}$, et al. Survey of attitudes and knowledge about science in medical students in southeast Europe. BMJ 2005;331:195-6.

13. Segal S, Lloyd T, Houts PS, Stillman PL, Jungas RL. Postgraduate medical activities. Acad Med 1990;65:530-3.

14. Farzaneh E, Amani F, Taleghani YM, Fathi A, Kahnamouei-aghdam F, Fatthzadeh-Ardalani G. Research barriers from the viewpoint of faculty members and students of Ardabil University of Medical Sciences, Iran, 2014. Int J Res Med Sci 2017;4:1926-32.

15. Nikrooz L, Rouzitalab M, Rayegan Shirazi AR, Naghizadeh MM, Taghavi F. Student research projects inhibiting factors from the students perspective. J Fasa Uni Med Sci 2012;2:113-9.

16. Ashtyani S, Shamsi M. Comparison of barriers to research activities forms the point of view of normal and talented students at Arak University of Medical Sciences. Edu Res Med Sci 2012;1: 26-32.

17. Kharraz R, Hamadah R, AlFawaz D, Attasi J, Obeidat AS, Alkattan W, et al. Perceived barriers towards participation in undergraduate research activities among medical students at Alfaisal University-College of Medicine: A Saudi Arabian perspective. Med Teach 2016;38:S12-8.

18. Zohoor A, Fekri A. Research barriers from the perspective of faculty members of Iran Medical University. Payesh J 2002;2:113-20.

19. Ashrafi-Rizi H, Zarmehr F, Bahrami S, Ghazavi-Khorasgani Z, Kazempour $Z$, Shahrzadi L. Study on research anxiety among faculty members of Isfahan University of Medical Sciences. Mater Sociomed 2014;26:356-9.

20. Mahmodabad M. A survey of Shahid Sadoughi University of medical sciences students' opinions about research barriers during university training. J Med Educ Dev 2013;6:63-70.

21. Siemens DR, Punnen S, Wong J, Kanji N. A survey on the attitudes towards research in medical school. BMC Med Educ 2010;10:4.

22. Amin TT, Kaliyadan F, Al Qattan EA, Al Majed MH, Al Khanjaf HS, Mirza $M$. Knowledge, attitudes and barriers related to participation of medical students in research in three Arab Universities. Edu Res Med Sci 2012;4:e43-56.

23. Ibrahim Abushouk A, Nazmy Hatata A, Mahmoud Omran I, Mahmoud Youniss M, Fayez Elmansy K, Gad Meawad A. Attitudes and perceived barriers among medical students towards clinical research: A cross-sectional study in an Egyptian medical school. J Biomed Edu 2016;2016:1-7.

24. Majumder MA. Issues and priorities of medical education research in Asia. Ann Acad Med Singapore 2004;33:257-63.

25. Sumathipala A, Siribaddana S, Patel V. Under-representation of developing countries in the research literature: Ethical issues arising from a survey of five leading medical journals. BMC Med Ethics 2004;5:E5.

26. Bagheri Majd R, Ghalavandi H, Miraghaei AA, Sedghi Bokani N, Bagheri Majd A. Analysis of gap of humanities studies in higher education. IJVLMS 2014;1:79-90. 
27. Hegde A, Venkataramana G, Kulkarni SB, Bhaskar NN, Jacob J, Gangadharappa SK. Attitudes, experiences, and barriers to research and publishing among dental postgraduate students of Bengaluru City: A cross-sectional study. J Ind Assoc Public Health Dent 2017;15:157.

28. Stange KC. Primary care research: Barriers and opportunities. J Fam Pract 1996;42:192-8.

29. Shekari G, Zavari M, editors. The main challenge for the research: lack of funds or research culture of Country. National Conference on Research and Technology; 2010 Available at: https://profdoc.um.ac.ir/ paper-abstract-1019336.html

30. Bocar AC. Difficulties encountered by the student-researchers and the effects on their research output (March 31, 2009). Available at SSRN: https://Ssrn.com/abstract=1612050 or http://dx.doi.org/10.2139/ ssrn. 1612050

31. Ghaffarzadeh S, Nazari H, Ghasemi R, Ahmadi Doyran Z. Status of research among medical students of Urmia University Medical Sciences in (Knowledge, Attitude and Practice). J Urmia Nurs Midwifery Fac 2011;9:400-6.

32. Safari Y, Navazeshkhah F, Azizi M, Ziaei M, Sharafi K. The effective factors on the postgraduate students' interest and participation in performing research activities-case study: Kermanshah University of Medical Science. Future Med Educ J 2015;5:3-9.

33. Karimian Z, Sabbaghian Z, Saleh Sedghpour B, Lotfi F. Internal obstacles in research activities: Faculty members' viewpoints in Shiraz University of Medical Sciences. Iran J Med Edu 2012;11:750-63.

34. Shavoon A, Jahed H. Identifying barriers to research activities in terms of faculty members of Tabriz. Sci Tech Policy 2012;4:49-64.

35. Ashrafi-Rizi H, Fateme Z, Khorasgani ZG, Kazempour Z, Imani ST. Barriers to research activities from the perspective of the students of Isfahan University of Medical Sciences. Acta Inform Med 2015;23:155-9.

36. Chakraborti C, Bourgeois III DJ, Gleeson E, Gunderson W. Identifying barriers to successful research during medical school. Med Educ Dev 2012;2:2.

37. Alsied SM, Ibrahim NW. Exploring challenges encountered by EFL Libyan learners in research teaching and writing. IAFOR J Lang Learning 2017;3:143-58.
38. Azizi N. A study of ways to improve research performance of humanities faculty members. J Manag Syst 2013;6:7-33.

39. Zohor A, Fekri A. Barriers from the viewpoint of research faculty of Medical Sciences at Iran University. Payesh Health Monitor 2003;2:113-20.

40. Memarpour M, Fard AP, Ghasemi R. Evaluation of attitude to, knowledge of and barriers toward research among medical science students. Asia Pac Fam Med 2015;14:1.

41. Khan H, Khawaja MR, Waheed A, Rauf MA, Fatmi Z. Knowledge and attitudes about health research amongst a group of Pakistani medical students. BMC Med Educ 2006;6:54.

42. Abedini S, Abedini S, Kamalzadeh H, Momeni E, Zare S. Faculty members of Hormozgan Medical College points of views about research barriers. Dena J 2009;4:51-8.

43. Joibari L, Sanagoo A. A mechanism for increasing the performance of medical students. J Qualit R Health Sci 2012;1:59-69.

44. Poornaseri S, Mohamadi M, Mozafari N, Dadkhah B, editors. [The views faculty \& students about Barriers Research in Ardebil University of Medical sciences in 2006]. Proceeding of the 9th National Conference on Medical Education; March 14-16; Yazd: Iran: 2007.

45. Russell CD, Lawson McLean A, MacGregor KE, Millar FR, Young AM, Funston GM. Perceived barriers to research in undergraduate medicine. Med Teach 2012;34:777-8.

46. Oliveira CC, de Souza RC, Abe EH, Silva Móz LE, de Carvalho LR, Domingues MA. Undergraduate research in medical education: A descriptive study of students' views. BMC Med Educ 2014; 14:51.

47. Edwards K. "Short stops": Peer support of scholarly activity. Acad Med 2002;77:939.

48. Houlden RL, Raja JB, Collier CP, Clark AF, Waugh JM. Medical students' perceptions of an undergraduate research elective. Med Teach 2004;26:659-61.

49. Alamodi AA, Abu-Zaid A, Anwer LA, Khan TA, Shareef MA, Shamia AA, et al. Undergraduate research: an innovative studentcentered committee from the Kingdom of Saudi Arabia. Med Teach 2014;36:S36-42. 